\title{
Thermomechanical process route to achieve high fracture toughness in Ti-17 forgings for high temperature applications
}

\author{
Mario Balzer ${ }^{1, *}$, Thomas Witulski ${ }^{1}$ \\ ${ }^{1}$ Otto Fuchs KG, Meinerzhagen, Germany \\ *Corresponding author: mario.balzer@otto-fuchs.com
}

\begin{abstract}
Mechanical properties of Ti-17 are typically strongly influenced by different thermomechanical process parameters such as applied strain, cooling rates and heat treatment temperatures and times. A variation of theses parameters allows the optimization of material properties. Today Ti-17 is mainly used for aero engine applications, where a high strength and good low cycle fatigue properties are needed up to $450^{\circ} \mathrm{C}$. For structural parts damage tolerance properties are the main focus and therefore fracture toughness and fatigue crack propagation are the main driving factors for the design.
\end{abstract}

In large forgings such as aero structural parts, the tempering cross section generally varies significantly, which makes it extremely challenging to achieve uniform properties in each area of the forging especially in case of low buy-to-fly ratio. The aim of this work is to develop a robust thermomechanical processing route for large Ti-17 die forgings with complex geometry and high fracture toughness requirements.

Hand forging trials with four different thermomechanical processing routes resulting in a lamellar microstructure have been performed and their strength and fracture toughness properties were studied. In addition, one die forging using a promising process route was manufactured and strength and fracture toughness were compared with values typically achieved for Ti6-4.

\section{Introduction}

Ti-17 is a $\beta$-rich $\alpha+\beta$ alloy which was developed for elevated temperature applications which are requiring a combination of high strength and decent fracture toughness such as fan and compressor disks for gas or aero turbine engines. This combination of mechanical properties can be adjusted by thermomechanical processing (TMP). Typical TMP is either a $\alpha+\beta$ forging route followed by double solution heat treatment below $\beta$-Transus Temperature $\mathrm{T}_{\beta}$ and aged or a $\beta$-forging at least in the last forging sequence followed by solution heat treatment and ageing $[1,2]$, while latter is a typical TMP for aero engine disks with the following heat treatment parameters: Solution heat treatment at $800^{\circ} \mathrm{C} / 4 \mathrm{~h} / \mathrm{WQ}$ followed by ageing at $615^{\circ} \mathrm{C}-650^{\circ} \mathrm{C} / 8 \mathrm{~h} / \mathrm{AC}$ $[2,3]$.

When damage tolerance is used as a design concept, high fracture toughness and a low fatigue crack propagation rate is required. In this case, a lamellar microstructure is generally preferable to a globular or bimodal microstructure [4]. Therefore at least one process of a TMP route should be performed above $\mathrm{T}_{\beta}$ to obtain a lamellar microstructure. In order to improve fracture toughness, various parameters can be adjusted. After $\beta$-forging a decreasing cooling rate increases fracture toughness [5]. When it comes to final heat treatment, lower solution heat treatment temperatures and higher ageing temperature increases fracture toughness [2,67]. Overall, fracture toughness is increasing with increasing acicular $\alpha$-content [2,6]. Also long and thick $\alpha$ platelets are contributing to high toughness [5]. By varying these parameters, fracture toughness between approx. $27 \mathrm{MPa} \sqrt{\mathrm{m}}$ and $96 \mathrm{MPa} \sqrt{\mathrm{m}}$ can be set, whereby strength decreases with increasing toughness [1-2,5-7].

When it comes to uniform properties within a forging and process stability in serial production, it is very challenging to control each relevant process parameter in a complex shaped die forging due to the variating tempering cross sections. The goal of the present work was to further increase fracture toughness beyond the values reported in literature under the boundary condition of process stability.

\section{Material and experiments}

Four hand and two die forgings with different thermomechanical process routes were produced by conventional forging techniques using hydraulic forging presses. As starting material a Ti-17 billet with a nominal diameter of $200 \mathrm{~mm}$ was used. The chemical composition and the $\mathrm{T}_{\beta}$ corresponding to the top and bottom of the initial ingot are shown in Table 1. In the hand forging trials, 
the billet was straight drawn into a rectangular block with a square cross section of $135 \mathrm{~mm}$. Whereby the die forgings were hand and die forged into a complex shape with a tempering cross section between $50 \mathrm{~mm}$ and $100 \mathrm{~mm}$. After forging different heat treatments were carried out, while temperatures, soaking times and cooling rates were kept constant. Forging and heat treatment parameters are indicated in Table 2.

Table 1 Chemical composition [wt.-\%] and $\beta$-Transus Temperature of the initial ingot

\begin{tabular}{|c|c|c|c|c|c|c|c|c|c|c|c|c|}
\hline & Al & Sn & $\mathbf{Z r}$ & Mo & $\mathrm{Cr}$ & O & $\mathbf{N}$ & $\mathrm{C}$ & H & $\mathbf{F e}$ & $\mathbf{T i}$ & $\mathbf{T}_{\boldsymbol{\beta}}\left[{ }^{\circ} \mathbf{C}\right]$ \\
\hline Top & 5,14 & 1,99 & 2,00 & 4,02 & 4,01 & 0,1198 & 0,0024 & 0,0056 & $<0,006$ & 0,04 & Bal. & 887 \\
\hline Bottom & 5,02 & 1,95 & 2,09 & 3,84 & 4,09 & 0,1072 & $<0,0020$ & 0,0052 & $<0,006$ & 0,04 & Bal. & 882 \\
\hline
\end{tabular}

Table 2 Forging and heat treatment parameters

\begin{tabular}{|cccc|}
\hline & Variante & Forging & Heat Treatment \\
\hline Hand forging trials & $\mathrm{HF} 1$ & $\alpha+\beta / \mathrm{AC}$ & $\beta$-annealed/AC + solution heat treated/AC + aged/AC \\
& $\mathrm{HF} 2$ & $\beta / \mathrm{AC}$ & direct aged/AC \\
& $\mathrm{HF} 3$ & $\beta / \mathrm{AC}$ & solution heat treated/AC + aged $/ \mathrm{AC}$ \\
& $\mathrm{HF} 4$ & $\beta / \mathrm{AC}$ & $\beta$-annealed/AC + aged $/ \mathrm{AC}$ \\
\hline Die forgings & $\mathrm{DF} 1$ & $\alpha+\beta / \mathrm{AC}$ & $\beta$-annealed/AC + solution heat treated/AC + aged/AC \\
\hline
\end{tabular}

After heat treatment, 2 tensile specimens each in longitudinal (L) and long transverse (LT) direction and 2 fracture toughness specimens each in L-T and T-L direction were taken from the hand forged blocks, while 3 tensile tests per direction (longitudinal (L), long transverse (LT) and short transverse (ST)) and temperature (room temperature, $300^{\circ} \mathrm{C}, 350^{\circ} \mathrm{C}, 400^{\circ} \mathrm{C}$ ) and 2 fracture toughness tests per direction (L-T, T-L, S-T) were performed on the die forgings. Room temperature and elevated temperature tests have been performed according to EN 2002-001 and EN 2002-002 respectively. Fracture toughness was determined by ASTM E399 using compact $\mathrm{C}(\mathrm{T})$ specimens. In addition, fatigue crack propagation tests in L-T and T-L direction were performed according to ASTM E647 in the $\Delta \mathrm{K}$ range between $10 \mathrm{MPa} \sqrt{\mathrm{m}}$ and $40 \mathrm{MPa} \sqrt{\mathrm{m}}$ using compact $\mathrm{C}(\mathrm{T})$ specimens at room temperature and $\mathrm{R}=0.1$. Macrostructure was revealed by an etchant consisting of $10 \mathrm{ml} \mathrm{HF,} 10 \mathrm{ml} \mathrm{HNO}_{3}$ and $80 \mathrm{ml} \mathrm{H}_{2} \mathrm{O}$ (comparable to ASTM E407 no.186) and microstructure by etchant ASTM E407 no.192. Grain size was determined by line intercept method according to ASTM E112.

\section{Results}

\subsection{Comparison of tensile test and fracture toughness test results of different TMP routes}

Table 3 shows the room temperature tensile test and fracture toughness test results of the four different TMP routes. In the $\beta$ forging variants, strength is increasing form HF2 to HF4, while elongation and fracture toughness in decreasing. The variant $\beta$ forging followed by direct ageing (HF2) and $\beta$-forging followed by solution heat treatment and ageing (HF3) show directiondependent properties for elongation and fracture toughness, where values in L / L-T direction are higher than in LT / T-L direction. $\beta$-annealing after $\alpha+\beta$ - (HF1) or $\beta$-forging (HF4) leads to isotropic properties. The $\alpha+\beta$-forging route followed by solution heat treatment and ageing (HF1) led to the lowest strength compared to the $\beta$-forging variants, whereby the average elongation is higher. 
Table 3 Measured test results from the Ti-17 hand forging trials. HF1: $\alpha+\beta$ forged $+\beta$-annealed + SHT + aged, HF2: $\beta$ forged+direct aged, HF3: $\beta$-forged + SHT+aged, HF4: $\beta$ forged $+\beta$-annealed + aged

\begin{tabular}{|c|c|c|c|c|c|c|}
\hline & \multicolumn{4}{|c|}{ RT Tensile Test } & \multicolumn{2}{|c|}{ Fracture Toughness } \\
\hline & Direction & $\begin{array}{c}\text { YS } 0.2 \% \\
\text { [MPa] } \\
\end{array}$ & $\begin{array}{c}\text { UTS } \\
{[\mathrm{MPa}]}\end{array}$ & $\begin{array}{c}\mathbf{A}_{5} \\
{[\%]}\end{array}$ & Direction & $\begin{array}{c}\mathrm{K}_{\mathrm{IC}} \\
{[\mathrm{MPa} \sqrt{ } \mathbf{m}]}\end{array}$ \\
\hline \multirow{4}{*}{ HF1 } & \multirow{2}{*}{$\mathrm{L}$} & 975 & 1066 & 13 & \multirow{2}{*}{ L-T } & 110,9 \\
\hline & & 970 & 1062 & 12,5 & & 111,7 \\
\hline & \multirow{2}{*}{ LT } & 964 & 1041 & 12,2 & \multirow{2}{*}{ T-L } & 106,2 \\
\hline & & 987 & 1059 & 9 & & 108,2 \\
\hline \multirow{4}{*}{ HF2 } & \multirow{2}{*}{$\mathrm{L}$} & 987 & 1070 & 14,2 & \multirow{2}{*}{ L-T } & (not tested) \\
\hline & & 989 & 1071 & 15,1 & & 135,5 \\
\hline & \multirow{2}{*}{ LT } & 989 & 1058 & 7,8 & \multirow{2}{*}{ T-L } & 121,9 \\
\hline & & 999 & 1067 & 7,7 & & 116,7 \\
\hline \multirow{4}{*}{ HF3 } & \multirow{2}{*}{$\mathrm{L}$} & 1061 & 1138 & 10,5 & \multirow{2}{*}{ L-T } & 121,2 \\
\hline & & 1042 & 1129 & 7,5 & & 120,1 \\
\hline & \multirow{2}{*}{ LT } & 1069 & 1157 & 5,4 & \multirow{2}{*}{ T-L } & 105,5 \\
\hline & & 1063 & 1156 & 6,2 & & 99,1 \\
\hline \multirow{4}{*}{ HF4 } & \multirow{2}{*}{$\mathrm{L}$} & 1118 & 1189 & 1,8 & \multirow{2}{*}{ L-T } & 82,1 \\
\hline & & 1102 & 1182 & 2,2 & & 80,7 \\
\hline & \multirow{2}{*}{ LT } & 1135 & 1219 & 2,9 & \multirow{2}{*}{$\mathrm{T}-\mathrm{L}$} & 74,1 \\
\hline & & 1142 & 1228 & 2,8 & & 76,0 \\
\hline
\end{tabular}

The relationship between yield strength and fracture toughness is plotted in Fig. 1. The four TMP routes selected covered a strength range between $950 \mathrm{MPa}$ and $1150 \mathrm{MPa}$ and a toughness range between $74 \mathrm{MPa} \sqrt{\mathrm{m}}$ and $135 \mathrm{MPa} \sqrt{\mathrm{m}}$. The typical relationship between toughness and strength can be determined, where the strength decreases with increasing toughness. It should also be noted that the strength level of the $\alpha+\beta$-forging route (HF1 and DF1) is about $100 \mathrm{MPa}$ lower for the same toughness level than the $\beta$-forging routes. In comparison between hand and die forgings - both $\alpha+\beta$-forged, $\beta$-annealed, solution heat treated and aged - achieved toughness of the hand forging is higher even if the strength level is the same.

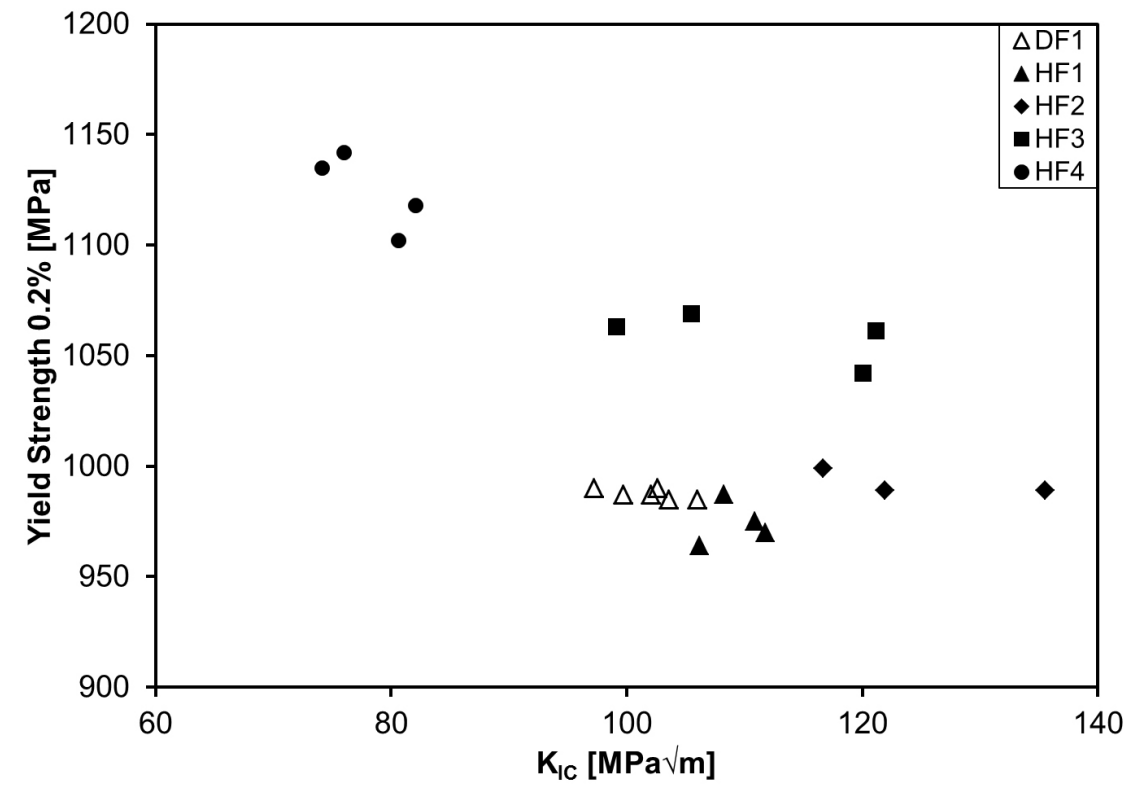

Figure 1 Results of RT yield strength over RT fracture toughness of 4 different TMP routes. DF1 and HF1: $\alpha+\beta$ forged $+\beta-$ annealed + SHT + aged, HF2: $\beta$-forged + direct aged, HF3: $\beta$-forged + SHT + aged, HF4: $\beta$ forged $+\beta$-annealed + aged 


\subsection{Die forging test results and property comparison with Ti6-4 die forgings}

Pictures of the macrostructure and microstructure of the die forged part are shown in Fig. 2 and 3. The macrostructure shows a fine and uniform prior $\beta$ grain size. Average prior $\beta$ grain size is $0.33 \mathrm{~mm}$, which is finer compared to a typical grain size for Ti6-4 $\beta$ annealed die forgings of $0.5 \mathrm{~mm}$ to $1.5 \mathrm{~mm}$. The microstructure consists of lamellar and basket weave structures with straight grain boundaries with thin grain boundary $\alpha$. The microstructures on the surface and in the core are the same, which means that no harmful surface effects such as die chill zones occurred. This is the expected microstructure for a $\beta$-annealed material. At higher magnification coarse primary $\alpha$ laths and $\beta$ laths can be detected in the SEM images (Fig. 3). Within the $\beta$ laths very fine secondary $\alpha$ phase has precipitated.

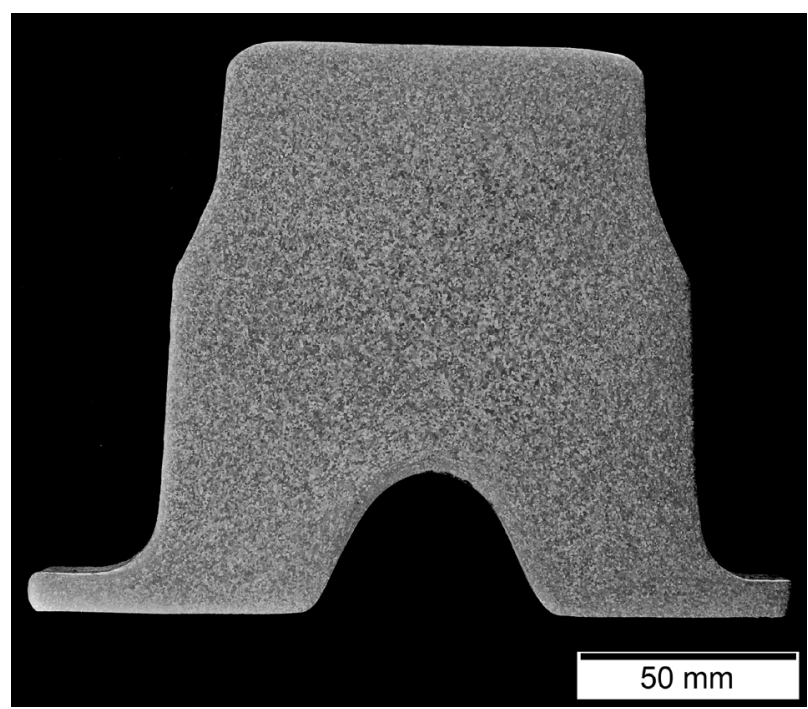

Figure 2 Macrostructure image of the Ti-17 die forging $\alpha+\beta$ forged $+\beta$-annealed $+\mathrm{SHT}+$ aged
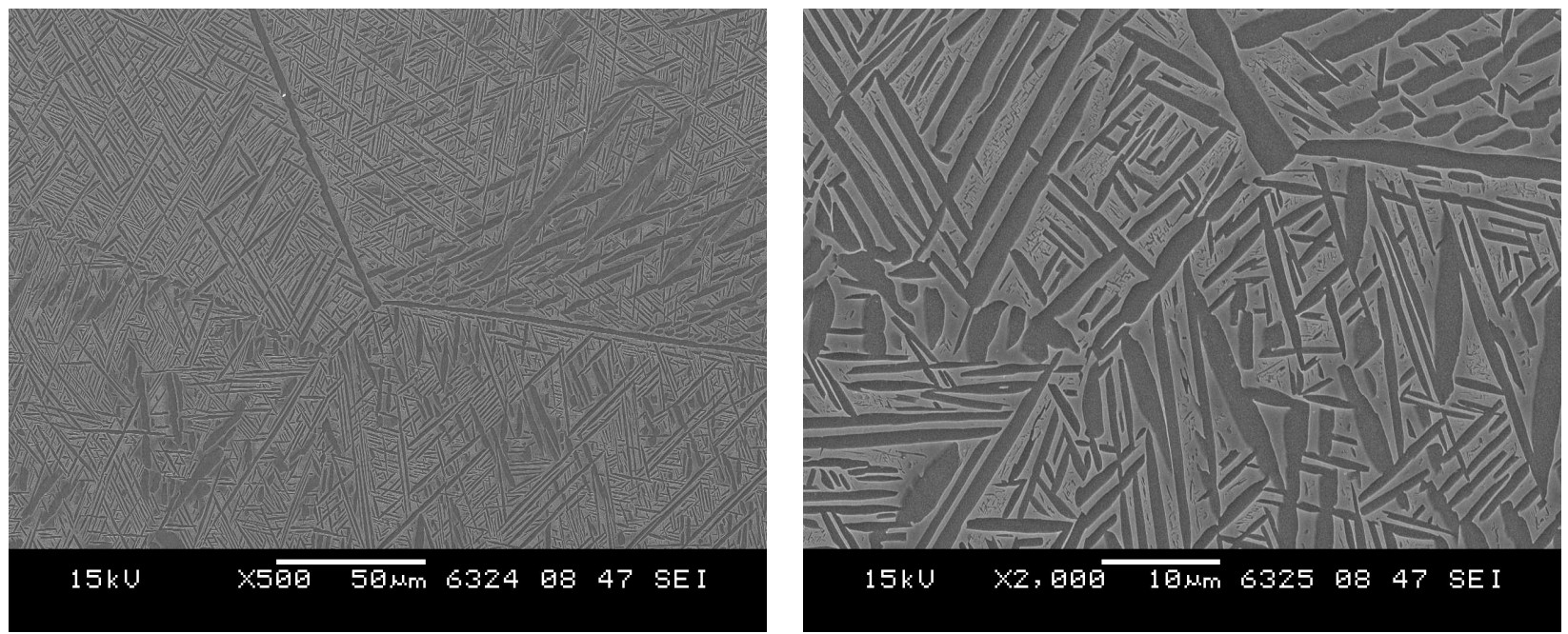

Figure 3 Microstructure SEM images (SE detector) of the Ti-17 die forging $\alpha+\beta$ forged $+\beta$-annealed + SHT + aged

Room temperature and elevated temperature test results are plotted in Fig. 4. In the temperature range considered between room temperature and $400^{\circ} \mathrm{C}$ the elongation is constantly between $11 \%$ and $12 \%$. Yield strength is decreasing from $988 \mathrm{MPa}$ at room temperature over $767 \mathrm{MPa}$ at $300 \mathrm{MPa}, 742$ at $350^{\circ} \mathrm{C}$ to $719 \mathrm{MPa}$ at $400^{\circ} \mathrm{C}$. The same trend applies also for ultimate tensile strength. The value drops from $1073 \mathrm{MPa}$ at room temperature to $875 \mathrm{MPa}$ at $400^{\circ} \mathrm{C}$. 


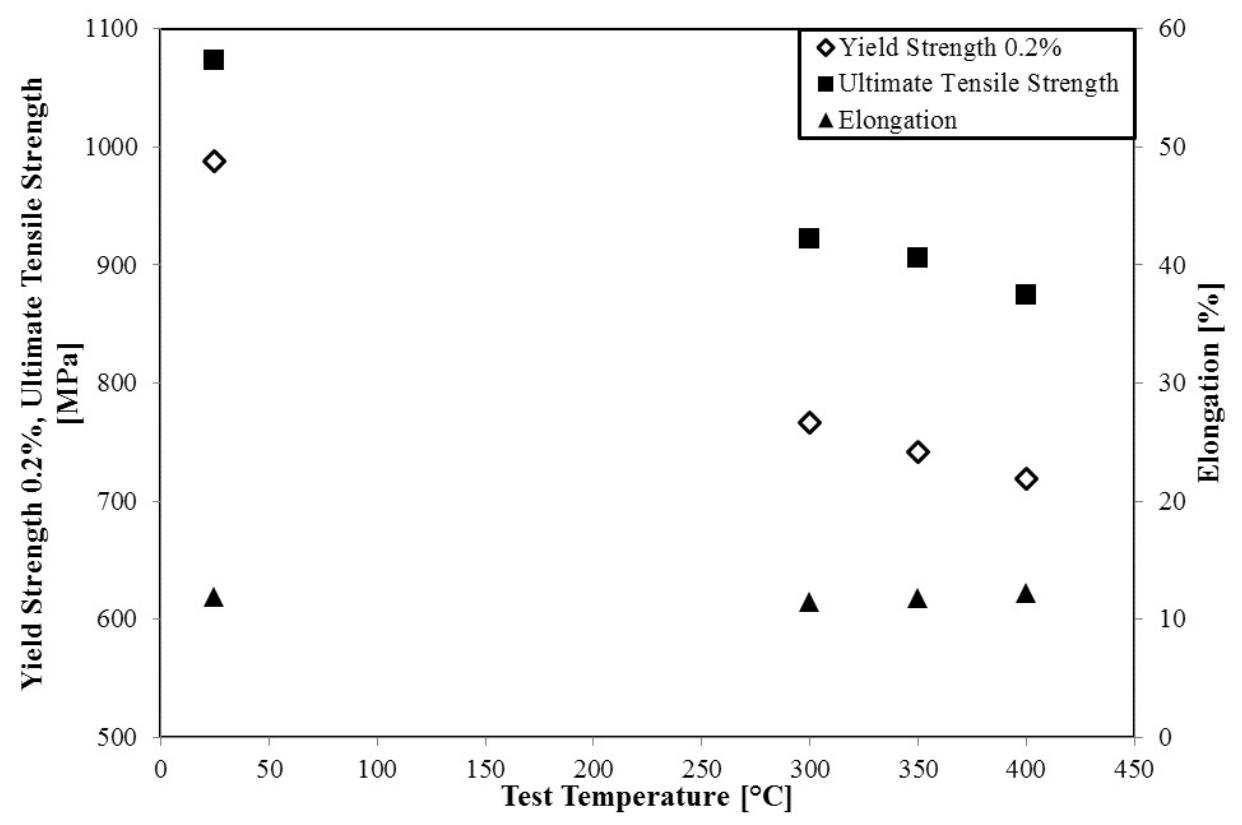

Figure 4 Average of 9 tensile test results per temperature as a function of temperature for a Ti17 die forging $\alpha+\beta$ forged $+\beta$ annealed+SHT+aged

A comparison of the already mentioned strength values with typical values from die forgings of a similar tempering cross section made of Ti6-4 and aero engine disks (Fig. 5) shows that the strength level of Ti6-4 $\beta$-annealed forgings is lowest and highest for the standard TMP route for Ti-17 aero engines. The TMP route used in this work led to strength level, which on average is about $100 \mathrm{MPa}$ higher than that of Ti6-4 and is in the upper range of Ti6- $4 \alpha+\beta$ processed forgings. The toughness level is similar to slightly superior to that of Ti6-4 $\beta$-annealed forgings (Fig. 6) and with values between $87 \mathrm{MPa} \sqrt{\mathrm{m}}$ and $112 \mathrm{MPa} \sqrt{\mathrm{m}}$, it is far above the typical range of the other two.

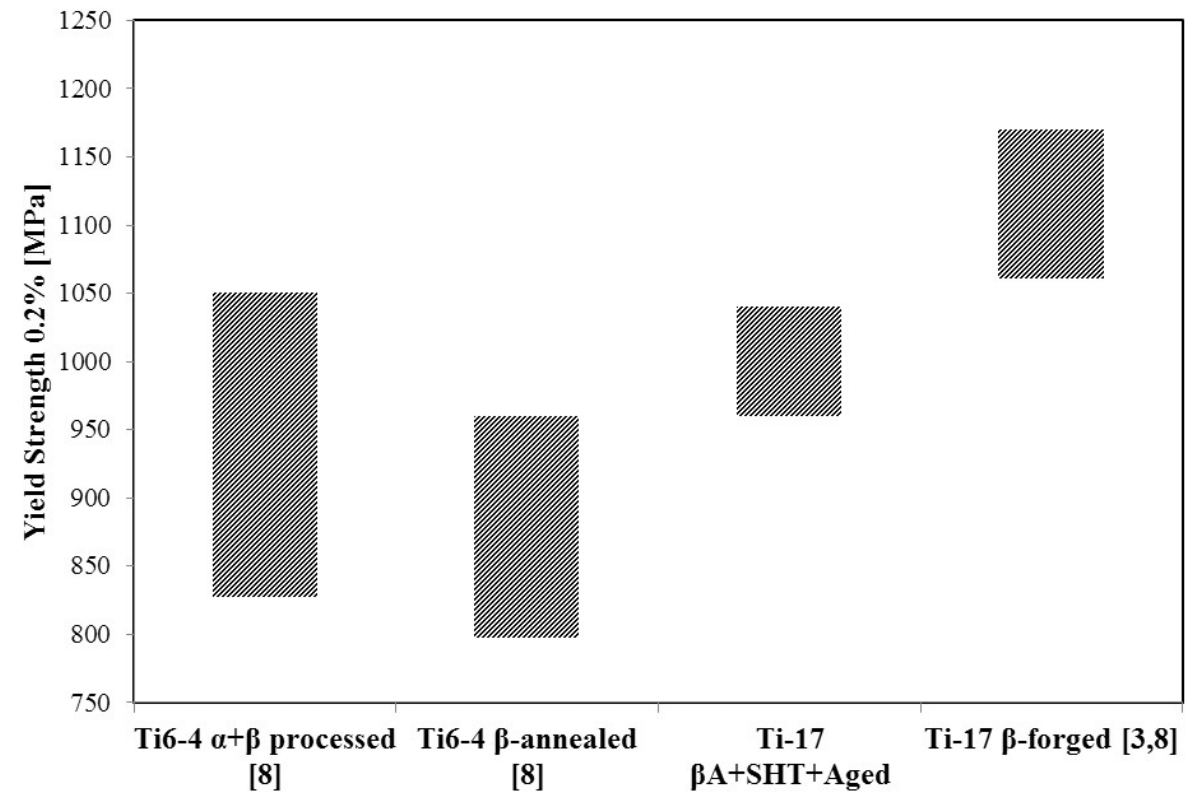

Figure 5 Comparison of obtained yield strength $0.2 \%$ between Ti6-4 and Ti-17 die forgings processed with different TMP routes. 


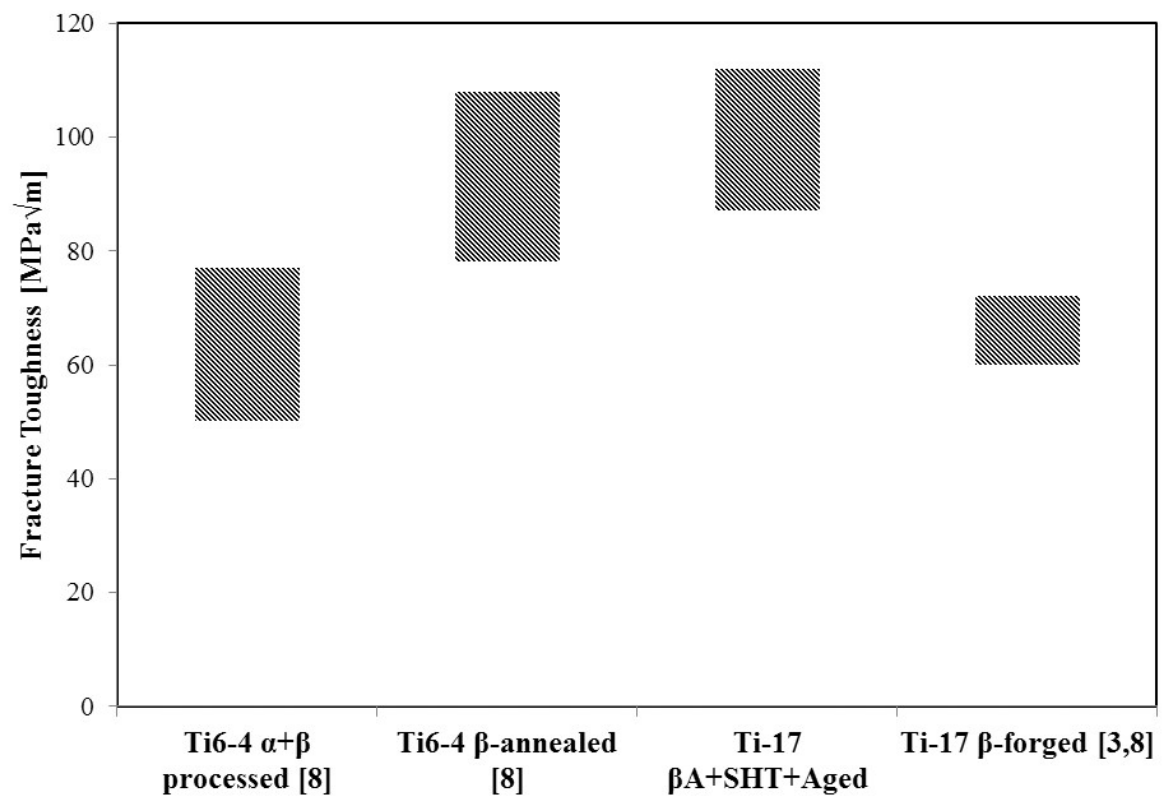

Figure 6 Comparison of obtained fracture toughness between Ti6-4 and Ti-17 die forgings processed with different TMP routes

Upper and lower scatter bands of the fatigue crack growth rates are shown in Fig. 7. The obtained results of the Ti-17 die forging are within the scatter band of Ti6-4 die forgings. In the $\Delta \mathrm{K}$ range between $10 \mathrm{MPa} \sqrt{\mathrm{m}}$ and $16 \mathrm{MPa} \sqrt{\mathrm{m}}$ the crack growth rate for is comparable to Ti6-4 $\alpha+\beta$-processed. However, the slope in this range is lower. At approx. $16 \mathrm{MPa} \sqrt{\mathrm{m}}$ the fatigue crack growth rate starts to lie on the upper bound of the Ti6$4 \beta$-annealed data. Overall, the fatigue crack growth rate of the chosen TMP route for Ti-17 is comparable to Ti6-4 data, but the Ti6-4 $\beta$-annealed remains superior.

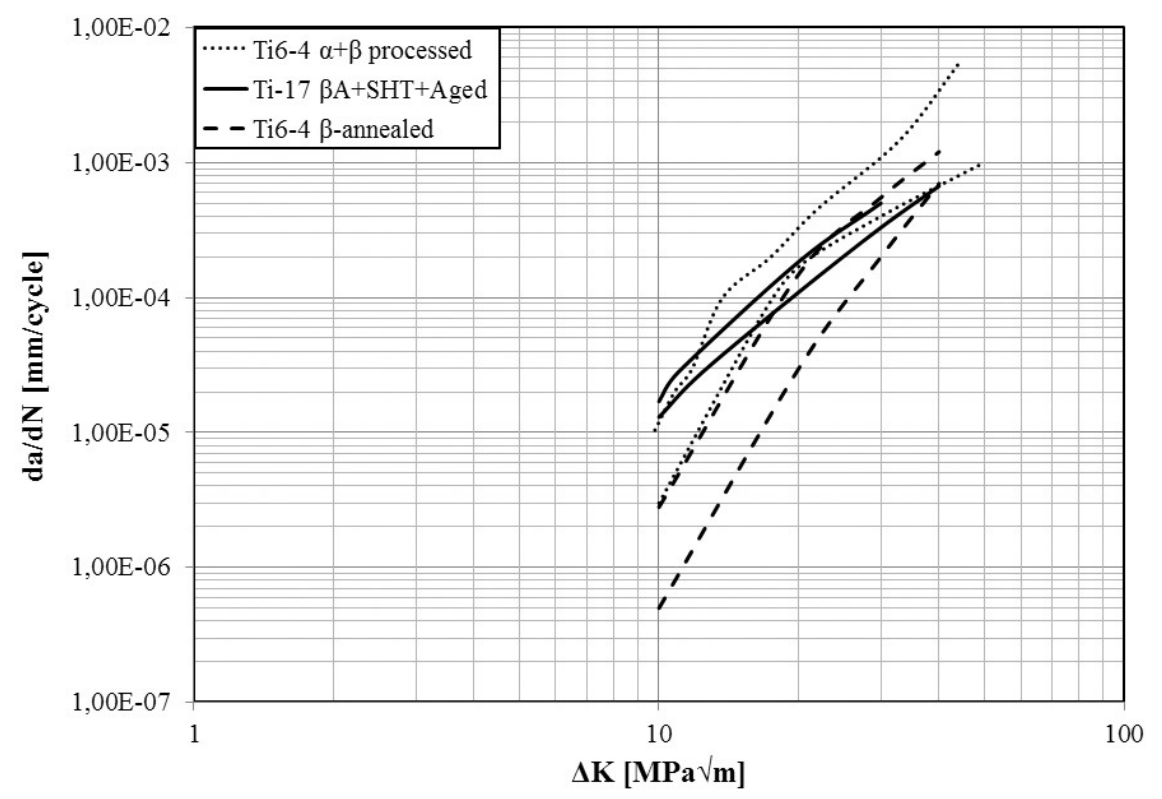

Figure 7 Comparison of scatter bands of the fatigue crack propagation rate $(\mathrm{R}=0.1)$ of $\mathrm{Ti6}-4$ [8] and the new Ti-17 TMP route 


\section{Summary and Conclusion}

Forging and heat treatment trials on Ti-17 were carried out to obtain a lamellar microstructure by either $\beta$-forging, $\beta$-annealing or both. After a final heat treatment consisting of solution heat treatment and/or ageing, tensile tests, fracture toughness tests were carried out and compared with each other. Finally, mechanical properties from a Ti-17 die forging were compared with typical values obtained in Ti6-4 die forgings. The following conclusion can be drawn:

- Different strength and toughness levels of Ti-17 can be adjusted by using different TMP routes, while the strength is decreasing with increasing toughness.

- Higher fracture toughness values could be achieved compared to values reported in literature

- Compared to the typical TMP route for Ti-17 engine disks, higher toughness up to $135 \mathrm{MPa} \sqrt{\mathrm{m}}$ can be achieved by slower cooling rates and higher ageing temperatures, whereby the strength level is approx. $100 \mathrm{MPa}$ lower. Therefore a wide range of properties can be adjusted depending on the requirements which are needed for specific applications.

- A $\alpha+\beta$-forging route followed by $\beta$-annealing leads to more uniform and isotropic properties compared to a $\beta$-forging route. Also the elongation is higher for this TMP route. On the contrary, the strength level is higher for all chosen $\beta$-forging routes.

- The microstructure of the selected $\alpha+\beta$-forging route led to a uniform microstructure consisting of lamellar and basket weave structures. Harmful surface effect such as die chill zones could not be observed.

- A wide range of mechanical properties can be covered by Ti-17 and that the required properties can be achieved by varying the forging temperatures, heat treatment temperatures, heat treatment cycles and cooling rates depending on the required properties. Yield strength can be adjusted between approx. 950-1160MPa and fracture toughness between approx. 60$135 \mathrm{MPa} \sqrt{\mathrm{m}}$. This is superior to values obtained in Ti6-4 forgings of a similar tempering cross section.

- The results of the fatigue crack growth rate between $10-40 \mathrm{MPa} \sqrt{\mathrm{m}}$ of the chosen $\alpha+\beta$ forging route are in the scatter band of Ti6-4 $\alpha+\beta$ processed and Ti6-4 $\beta$-annealed, whereby the crack growth rates of Ti6- $4 \beta$-annealed are superior

- The approach of $\beta$-annealing instead of $\beta$-forging should also be effective for other $\alpha+\beta$ alloys such as Ti-6242 and Ti6246, when high toughness is required.

\section{$\underline{\text { References }}$}

[1] W.F.Brown, H.Mindlin,C.Y.Ho, Aerospace Structural Metals Handbook, Volume 4 (1996) 3724 p1-8

[2] R.Boyer, G.Welsch, E.W.Collings, Materials Properties Handbook: Titanium Alloys, $4^{\text {th }}$ Edition (2007), p.453-463

[3] O. Roder, D. Helm, S. Lütjering, G. Fischer, G. Terlinde, T. Witulski, Ti-2003 Science and Technology Volume III (2003) p. $1369-2032$

[4] M.Peters, C.Leyens, Titan und Titanlegierungen, $4^{\text {th }}$ Edition (2011), p.13

[5] X.Shi, W.Zeng, Q.Zhao, Materials Science and Engineering A (2015) p.543-550

[6] T.Kida, H.Ohyama, S.Ishigai, S.Masaki, T.Ikushima, Titanium'99: Science and Technology (1999) p.513-520

[7] M.Ortmayr, E.A.Werner, W.Horvath, Euromat 99, 1 (1999) p.218-224

[8] Database of Otto Fuchs KG, unpublished data (2019) 